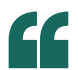

I am able to sketch a structure, synthesize and test it within a matter of weeks

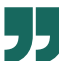

MOLECULAR MOTORS

\section{Roll this way}

The conversion of chemical energy to kinetic energy by motor proteins is a feature of all life. An archetypal example is the walking-like motion of the motor protein kinesin along microtubule filaments while transporting molecular cargo around cells. Now, Khalid Salaita and co-workers from Emory University have built a motor using self-assembled 'DNA origami' that can move over micrometre distances and at nanometre per second speeds.

"If we can create efficient molecular machines, then you could envision making nanoscale robots to help in manufacture or in drug delivery and even in the synthesis of complex polymers," says Salaita. "But for the moment, this remains in the realm of science fiction because we still don't know the basic rules of how to build processive and autonomous machines and motors."

Salaita and co-workers' motor is constructed using DNA origami; an approach that affords the possibility of rapid prototype design and testing. "I am able to sketch a structure, synthesize and test it within a matter of weeks - a situation that is close to impossible in the traditional synthetic organic chemistry realm," he says.
The motor they describe now self-assembles from 16 DNA double helices into a cuboidal structure with dimensions $10 \mathrm{~nm} \times 10 \mathrm{~nm} \times 130 \mathrm{~nm}$. Each of the large rectangular faces then features 36 single-stranded DNA legs. These legs bind to a surface functionalized with complementary single-stranded RNA. The motor moves by the legs being released from one binding site and attaching to a new one.

The design enables the motor to move unidirectionally on the surface by the so-called burnt-bridge Brownian ratchet mechanism. A binding event between the motor and a surface site triggers the destruction of that surface site, driving motion towards fresh new binding sites.

In this particular case, the motion is driven by the enzyme RNase $\mathrm{H}$. This enzyme specifically cleaves the RNA-DNA duplex from the surface. The small RNA fragment then dissociates from the DNA leg, leaving the leg free to bind to a new point on the surface, but cannot move backwards as the RNA functionalization has been 'burnt' away. "The movement is the result of a conundrum," says Salaita.
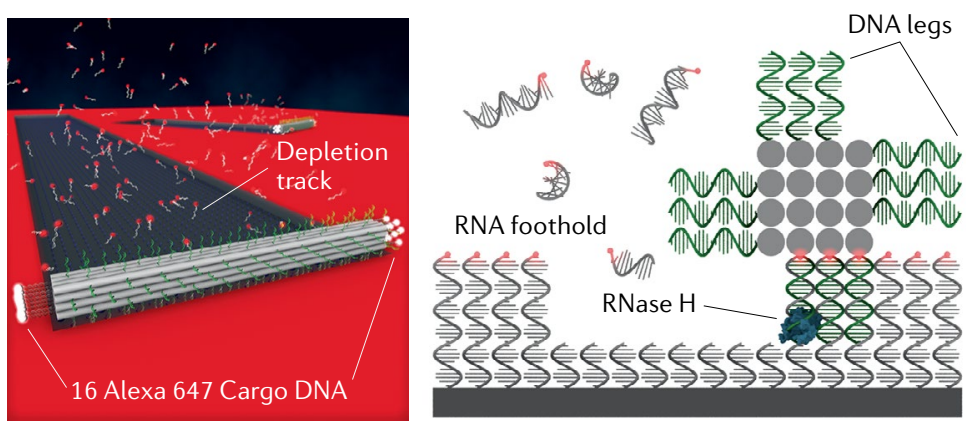

Credit: Adapted from Bazrafshan, A. et al. Angew. Chem. Int. Ed. https://doi.org/10.1002/anie.201916281 (2020), Wiley-VCH.
"The DNA legs have a high affinity for the RNA, but as soon as they bind, this triggers RNA hydrolysis. The motor then moves as the DNA legs seek out fresh RNA binding sites."

Previous motors that move in this fashion had only a small number of legs and moved slowly across surfaces — and often only took a few steps before dissociating from the surface or track completely. "We speculated that we might improve this by designing motors that roll across the surface rather than 'walk' or slide," explains Salaita. "The large number of DNA legs on each face avoids dissociation from the track, while the rigid rod-like shape helps ensure that it rolls in a straight line," he says.

The rapid prototyping capabilities of the DNA origami assembly enabled the team to investigate a number of different motor designs. The presence of DNA legs on all four faces of the motor is the key to its ability to roll quickly across the surface.

Motors with legs missing from one or two faces moved progressively less quickly across the surface and those with legs on only one face stopped rolling altogether, returning the slow sliding motion of much earlier designs. Motors built with flexibility in the central rod-like core also moved more slowly but, importantly, less linearly. "We were surprised to learn that reducing the overall number of legs didn't change the speed of rolling," says Salaita. "We had anticipated that decreasing the number of legs would increase velocity as it would require fewer cleavage events per step. Instead, we found that motor performance increases with leg density and independently of the absolute number of legs."

Stephen G. Davey

ORIGINAL ARTICLE Bazrafshan, A. et al. Tunable DNA origami motors translocate ballistically over $\mu \mathrm{m}$ distances at $\mathrm{nm} / \mathrm{s}$ speeds. Angew. Chem. Int. Ed. https://doi.org/10.1002/anie.201916281 (2020) 